Research Article

\title{
Study on Optimization of Delay Method of Wedge Cut Blasting in Tunnel
}

\author{
Wenle Gao $\mathbb{D}^{1},{ }^{1}$ Zhicheng Liu $\left(\mathbb{D},{ }^{1}\right.$ Yanping Wang, ${ }^{1}$ Zhenwei Yan, ${ }^{2}$ and Zehua Zhang ${ }^{3}$ \\ ${ }^{1}$ College of Civil Engineering and Architecture, Shandong University of Science and Technology, Qingdao 266590, China \\ ${ }^{2}$ Shandong Wancheng Group Co., Ltd., Linyi 276000, China \\ ${ }^{3}$ College of Pipeline and Civil Engineering, China University of Petroleum (East China), Qingdao 266580, China
}

Correspondence should be addressed to Zhicheng Liu; lzctop@163.com

Received 31 August 2021; Revised 5 October 2021; Accepted 8 October 2021; Published 23 November 2021

Academic Editor: Traian Mazilu

Copyright ( $\odot 2021$ Wenle Gao et al. This is an open access article distributed under the Creative Commons Attribution License, which permits unrestricted use, distribution, and reproduction in any medium, provided the original work is properly cited.

Relying on the entrance section of a high-speed railway tunnel blasting project, the fluid-solid coupling algorithm based on ANSYS/LS-DYNA was used to optimize the parameters of wedge cut blasting, and the vibration could be reduced on the basis of ensuring the blasting effect. Through the combination of visual numerical simulation results and rock-breaking mechanism of wedge cut blasting, the maximum vibration velocity of different monitoring points in the model under different segmented time delay was analyzed. The results show that the best method for detonation is dividing the blastholes into three segments from upper to lower and dividing the left and right symmetrical blastholes into one segment. When the delay time is $10 \mathrm{~ms}$, the average vibration reduction ratio is the best, which is reduced by $18 \%$ compared with the six-hole simultaneous blasting. In addition, the actual surrounding rock stress has a clamping effect on the cut blasting area. The wedge cut blasting footage obtained by numerical simulation was basically consistent with the field results, which proved that the model is reasonable and effective. This study intuitively and accurately demonstrated the process of cut blasting, the superposition curve of vibration velocity and the vibration reduction results under different delay times, and the effect of cut blasting. The results can be directly applied to similar projects, and the optimal blasting parameters and related issues can be solved more accurately with the help of this engineering analysis method.

\section{Introduction}

In the process of tunnel construction, mechanical excavation methods such as Tunnel Boring Machines (TBM) have disadvantages such as high maintenance investment, inconvenient distribution of equipment parts, difficulty in assembly on-site, and poor adaptability to various types of surrounding rock. The drilling and blasting method, which is another tunnel excavation method, has significant advantages such as better geological adaptability and less equipment investment. However, it inevitably involves harmful effects such as earthquakes, noise, air shock waves, gun smoke, and blasting flying rocks. Blasting vibration is the most harmful effect on the environment in tunnel blasting construction. Therefore, in order to improve the quality of the project and ensure the safety of the surrounding environment, blasting vibration effects need to be optimized urgently.

In order to reduce the intensity of blasting vibration, the optimization of blasting detonation methods and parameters has been conducted. Kumar and Dohyun Park et al. $[1,2]$ summarized and analyzed the optimal blasting parameters. Verma and $\mathrm{Li}$ et al. $[3,4]$ studied the damage to surrounding rock caused by excessive blasting vibration intensity. Trivino [5] found that the location of the detonation points has a certain influence on the blasting vibration. Onederra et al. [6] concluded that the damage area of the crushed medium at the orifice is larger than that at the bottom of the hole in the case of detonation at the bottom of the hole. Xie et al. [7] found that the superposition of the stress wave on the free surface and the reflected longitudinal wave caused damage to the joint near the orifice. Wenbo $\mathrm{Lu}$ 
et al. [8] found that stronger blasting vibration will be caused due to the clamping effect of cut blasting. And because of the limited power of mine explosive, the difficulty of cut blasting increases significantly with the hole depth [9]. Yu Stepanov [10] and Taran et al. [11] combined engineering blasting projects and used experimental research methods to obtain the calculation formula for the fracture range of the rock and proposed a calculation method of the cut length suitable for various mining conditions. Chakraborty et al. [12-14] proposed a more effective double wedge cut blasting method. Bjorn Zakrisson et al. [15] simulated the explosion load and structural deformation of a near-field explosion in the air using a fluid-solid coupling explosion numerical simulation method. Ma [16] used the wedge cut blasting finite element simulation to study the fracture mode of the cut model and explore the expansion and evolution process of the cut cavity. Yang [17] investigated the stress evolution and resultant rock damage arising from millisecond-delay blasting under the combined effects of in situ stress redistribution. The vibration effect generated by cut blasting is the largest in tunnel blasting construction, due to the large amount of charge. So it is of great significance to reduce the vibration effect of cut blasting. Many measures need to increase the number of cutting holes, change the conventional arrangement of cutting holes, or shorten the blasting footage, resulting in increased engineering costs and reduced tunnel excavation efficiency, making it difficult to effectively apply to tunnel cyclic blasting operations. It is extremely important to find a tunnel cut blasting method that can effectively reduce the effect of blasting vibration and ensure construction efficiency.

The method combining engineering fields investigation and numerical simulation is conducted in this study. A three-dimensional model of the local wedge-shaped cutting holes of the tunnel face was established by ANSYS/LSDYNA software, and the model boundary load was applied by theoretically studying the surrounding rock stress. Through the fluid-solid coupling algorithm, the rock breaking and crack propagation, the cut blasting rockbreaking effect, and the blasting footage in the three-dimensional model were simulated; additionally, the comparison between the actual project and simulation was conducted to analyze and verify the feasibility and accuracy of the model. Combining existing research and using numerical simulation methods to systematically study the rockbreaking mechanism of wedge cut blasting, the detonation sequence and segmented delay time of cutting holes in the engineering project were optimized, and blasting vibration was reduced effectively on the premise of ensuring successful cutting.

\section{Project Overview}

This tunnel is a single-hole double-line tunnel. The entrance section of the tunnel is divided into two parts: open-cut tunnel and subsurface excavation. The open-cut tunnel is about $38 \mathrm{~m}$ long and the $\mathrm{V}$-level surrounding rock volume of it is about $7500 \mathrm{~m}^{3}$; the length of the underground excavated part is about $2137 \mathrm{~m}$, of which the $\mathrm{V}$-level surrounding rock volume is about $23000 \mathrm{~m}^{3}$. The whole tunnel is located in the underground karst vertical seepage zone, and the surface water and groundwater are not corrosive to the concrete structure. The tunnel is located in a Zhongshan landform area with low tectonic erosion and denudation. The tunnel site is overlying the Quaternary Holocene cave accumulation layer and alluvial layer. The underlying bedrock is the Lower Ordovician Dawanian limestone with dolomite, breccia limestone, argillaceous limestone, and local Yanshanian diorite porphyry intrusive rocks.

According to the geological conditions of the tunnel and the original design support parameters, the level III surrounding rock of the subsurface excavation section shall be excavated by the full-section method, the level IV surrounding rock shall be excavated by the two-step method, and the level $\mathrm{V}$ surrounding rock shall be excavated by the three-step method plus temporary invert blasting, that is, a technology of step blasting that divides the design section of the tunnel into four excavations and advances different parts in steps. The rock was constructed by drilling and blasting, and the surrounding holes were smoothly blasted. The excavation sequence is upper step $\longrightarrow$ middle step $\longrightarrow$ lower step $\longrightarrow$ inverted arch.

Considering the stability of grade $\mathrm{V}$ surrounding rock during blasting construction, one-time blasting footage should be controlled. The one blasting footage $L$ is set to $1.36 \mathrm{~m}$, and the blast hole utilization rate is set to $85 \%$. On this basis, the drilling depths of the cutting holes, auxiliary holes, peripheral holes, and bottom plate holes are designed, respectively. The diameter of all blastholes on the upper steps is determined by the drilling machine, and they are all $40 \mathrm{~mm}$. The arrangement of blastholes on the upper steps of grade $\mathrm{V}$ surrounding rock and the setting of segmented delay are shown in Figures 1 and 2.

The blasting parameters of the upper steps cutting holes of grade $\mathrm{V}$ surrounding rock are shown in Table 1.

All blast holes on the upper steps were set to a reverse detonation design continuous charge structure, explosives were continuously packed along the axis of the blasthole, and the sealing quality should be ensured.

\section{Numerical Simulation Research}

3.1. Finite Element Model and Algorithm. According to the actual working conditions of the project, geometric models of fluid and solid structures have been established by ANSYS. Because the model is symmetrical, the establishment of the model has been completed by the mirror function of ANSYS. The geometric model built is shown in Figures 3 and 4 .

Through the fluid-solid coupling method, explosives and other fluid materials were calculated using the ALE algorithm, and the solid structures were calculated using the Lagrange algorithm. This method allows fluid materials such as explosives to flow in the ALE unit during the simulation without grid distortion. The 3D SOLID 164 element defined by 8 nodes was selected. Mapping meshing was selected as the main method, and sweeping meshing was also used. Gradual meshing was used for rock parts, which reduced the 


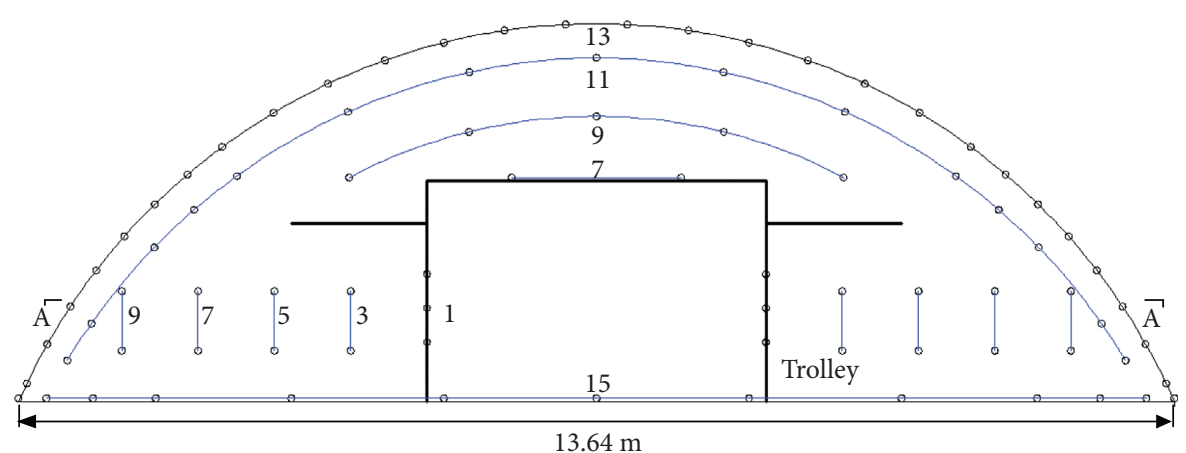

FIgURE 1: Layout of upper steps blastholes on the grade V surrounding rock and setting of segmented delay.

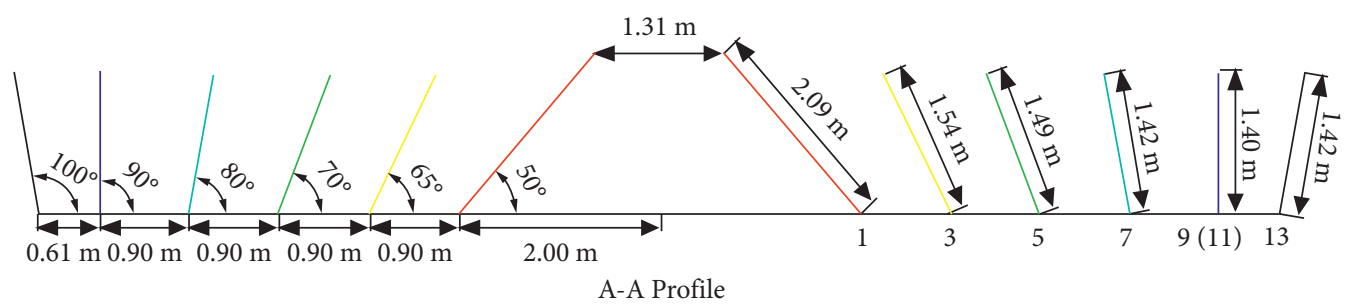

FIGURE 2: Sectional view of upper steps blast holes layout in grade V surrounding rock.

TABLE 1: Statistic table of cutting holes blasting parameters of upper steps in grade V surrounding rock.

\begin{tabular}{|c|c|c|c|c|c|c|c|c|c|}
\hline Segment & $\begin{array}{c}\text { Blasthole } \\
\text { name }\end{array}$ & $\begin{array}{l}\text { Detonator } \\
\text { extension time } \\
(\mathrm{ms})\end{array}$ & $\begin{array}{l}\text { Number of } \\
\text { blast holes } \\
\text { (piece) }\end{array}$ & $\begin{array}{l}\text { Hole } \\
\text { depth } \\
(\mathrm{m})\end{array}$ & $\begin{array}{l}\text { Hole } \\
\text { spacing } \\
(\mathrm{cm})\end{array}$ & $\begin{array}{l}\text { Charge } \\
\text { length } \\
(\mathrm{m})\end{array}$ & $\begin{array}{l}\text { Single- } \\
\text { hole } \\
\text { charge } \\
(\mathrm{kg})\end{array}$ & $\begin{array}{c}\text { Same deferred } \\
\text { explosive } \\
\text { charge }(\mathrm{kg})\end{array}$ & $\begin{array}{c}\text { Number of } \\
\text { detonators with } \\
\text { same extension } \\
\text { (piece) }\end{array}$ \\
\hline 1 & $\begin{array}{l}\text { Cutting } \\
\text { hole }\end{array}$ & 0 & 6 & 2.09 & 40 & 1.46 & 1.50 & 9.00 & 6 \\
\hline
\end{tabular}

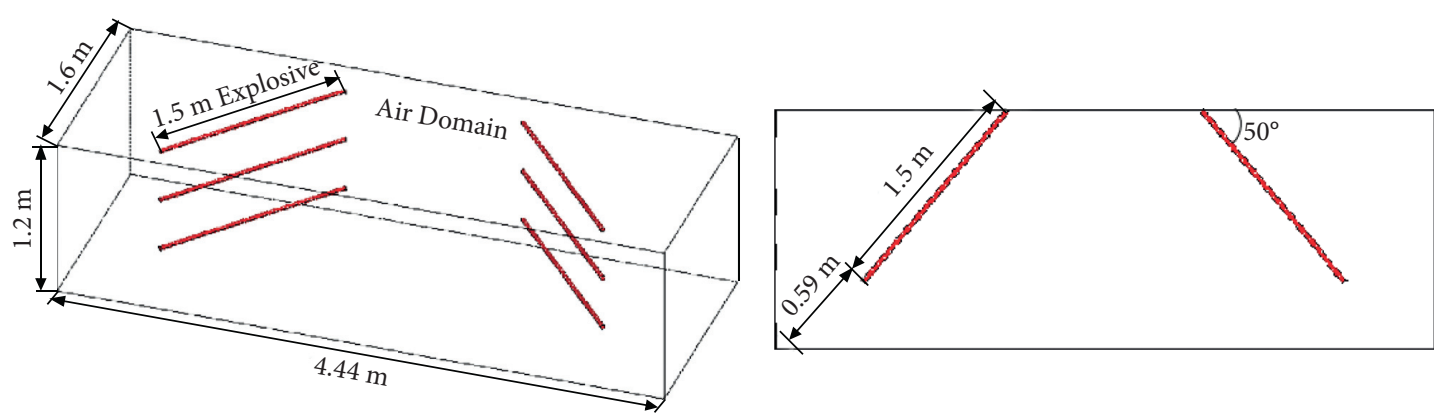

FIgURE 3: Geometry model of fluid structure.

solution time while ensuring the quality of meshing and the accuracy of calculation results [18].

Although the failure parameter $F$ s in the HJC constitutive model can better describe the failure characteristics of the element under compression, it is not ideal for the determination of tensile failure [19]. So it is necessary to add external failure types to accurately describe the blasting damage and destruction process of rock materials [20]. Defining different invalidation types through the LS-DYNA keyword *MAT_ADD_EROSION and setting the control parameter threshold of this keyword can realize that the element grid disappears when the explosion effect of the rock mass reaches the set threshold, thereby obtaining the simulation effect of crack propagation.

The four components obtained from the grid model (airfield, explosives, rocks, and gun mud) have been divided into 759456 unit grids, as shown in Figure 5.

3.2. Material Model and Parameters. Air materials are described by *MAT_NULL material constitutive model and linear polynomial state equation 


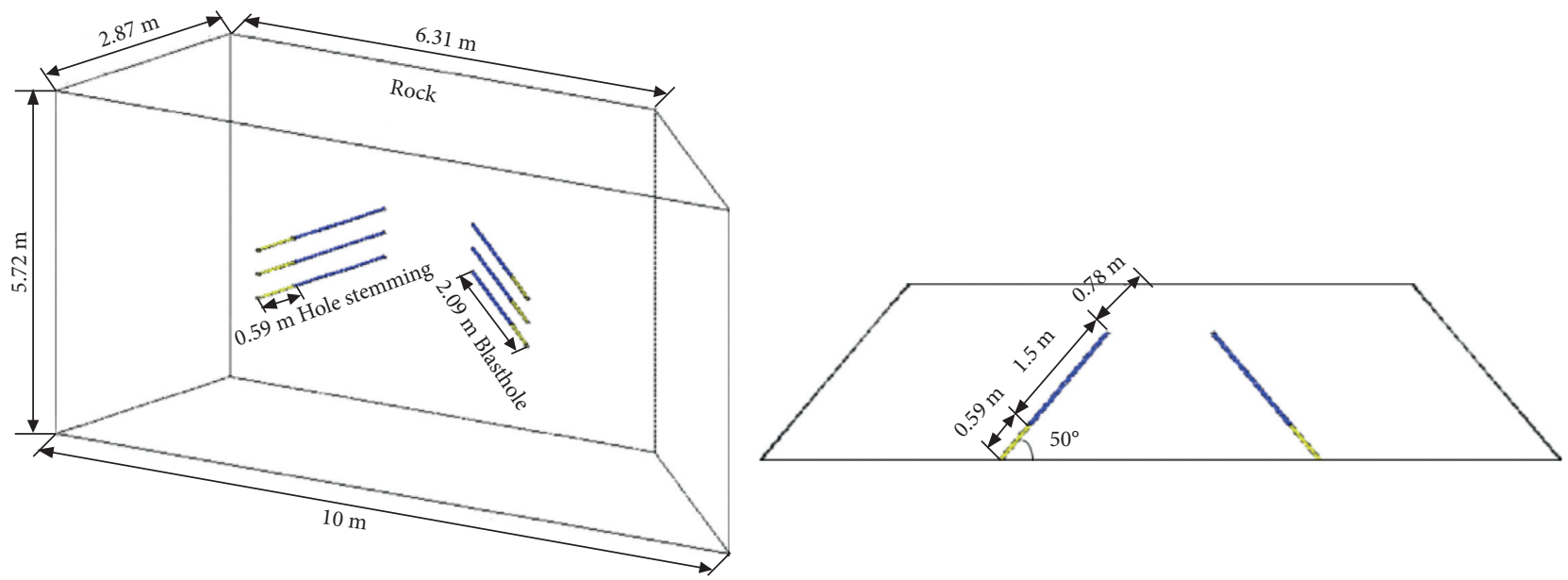

Figure 4: Geometric model of solid structure.

* EOS_LINEAR_POLYNOMIAL [21], and the parameters of air are listed in Table 2.

According to the relevant data of the on-site geological survey, it is determined that the blasting rock is mainly limestone.

The

* MAT_JOHNSON_HOLMQUIST_CONCRETE material constitutive model is used for numerical simulation calculation [22]. This constitutive model can effectively reflect the physical process and mechanical behavior of rock components under explosive impact loads, and the parameters of rock mass are listed in Table 3.

The specific value of the failure parameter in the constitutive model can be known from Sun Qiran's [23] related research on this:

$$
\begin{aligned}
F_{S} & =f\left(P_{R}\right) 1_{\text {max }_{\text {max }}^{* * D 2}}, \\
P_{R}^{*} & =\frac{P_{R}}{f_{c}}, \\
T^{*} & =\frac{T}{f_{c}},
\end{aligned}
$$

where $P_{R}$ is the impact pressure on the blasthole rock wall, $\mathrm{Pa} ; T$ is the maximum stretching hydrostatic pressure, $\mathrm{Pa} ; f_{c}$ is the quasiuniaxial compressive strength, $\mathrm{Pa} ; D_{1}{ }^{\prime} D_{2}$ is the damage constant.

In accordance with the study of actual engineering, only the impact pressure on the blasthole rock walls when uncoupled charges were studied and its value could be calculated by

$$
P_{R}=\frac{1}{8} \rho_{E 0} D^{2}\left(\frac{d_{c}}{d_{b}}\right)^{6}\left(\frac{l_{c}}{l_{b}}\right)^{3} n,
$$

where $\rho_{E 0}$ is the density of explosive, $\mathrm{kg} / \mathrm{m}^{3} ; D$ is the explosive velocity, $\mathrm{m} / \mathrm{s} ; d_{c}{ }^{\prime} d_{b}$ is the charge diameter and blast hole diameter, $\mathrm{mm} ; l_{c}{ }^{\prime} l_{b}$ is the charge length and blast hole length, $\mathrm{m} ; n$ is the pressure magnifying coefficient; take 8 11.

Combining formula (4), we can get $P$ as $1855.38 \mathrm{MPa}$ and further combine formulas (1)-(3) to get $F_{S}$ as 1.24.
Explosives are described by * MAT_HIGH_EXPLOSIVE_BURN material constitutive model and *EOS_JWL state equation $[24,25]$. The explosive material is No. 2 rock emulsion explosive which is the same as the blasting site. The physical and mechanical parameters and the JWL state equation parameters are shown in Table 4.

The blasting mud material is described by the * MAT_DRUCKER_PRAGER material constitutive model, which can effectively reflect the dynamic mechanical behavior of the blasting mud when subjected to an explosion impact load. Its physical and mechanical parameters are shown in Table 5.

3.3. Surrounding Rock Stress. The numerical simulation model is the cutting hole area of the tunnel face. The rock mass here is $41.99 \mathrm{~m}$ deep and is inevitably affected by the stress of the surrounding rock. A large amount of measured data shows that the vertical stress value is often greater than the rock mass gravity. For the scale factor of $\lambda_{0}=\sigma_{V} / \gamma H$, China's actual measurement $\lambda_{0}<0.8$ accounted for $13 \%$, $\lambda_{0}=0.8 \sim 1.2$ accounted for $17 \%, \lambda_{0}>1.2$ accounted for more than $65 \%$, and most of the above data were measured within $200 \mathrm{~m}$ depth and the deepest point reached $500 \mathrm{~m}$ [26]. For the initial stress of the rock mass, $\lambda_{0}$ is selected as 1.2 to quantify the vertical stress of the model, which is

$$
\sigma_{V}=\lambda_{0} \gamma H
$$

where $\sigma_{V}$ is the vertical stress, $\mathrm{Pa}$; $\gamma$ is the weight of the overlying rock, $\mathrm{N} / \mathrm{m}^{3}$; Hdenotes depth, $\mathrm{m}$.

It is known that the depth of the tunnel face is $41.99 \mathrm{~m}$, the lithology of the grade $\mathrm{V}$ surrounding rock is argillaceous limestone, its natural gravity is $22540 \mathrm{~N} / \mathrm{m}^{3}$, and the vertical stress is $1.14 \mathrm{MPa}$ from equation (5).

The measured horizontal stress data of various countries in the world show that its value is generally greater than $[\mu /(1-\mu)] \times \gamma H$ caused by the Poisson effect and is greater than or close to the measured vertical stress. The ratio of the maximum horizontal stress $\sigma_{H 1}$ to $\sigma_{V}$ is used to express the lateral pressure coefficient $\left(\lambda_{1}=\sigma_{H 1} / \sigma_{V}\right)$; 


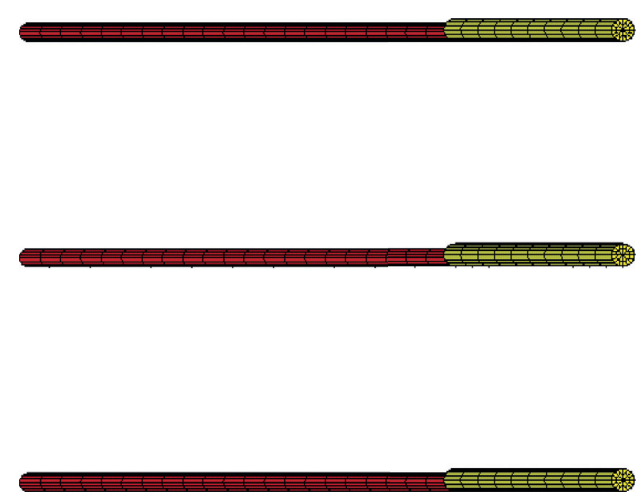

(a)

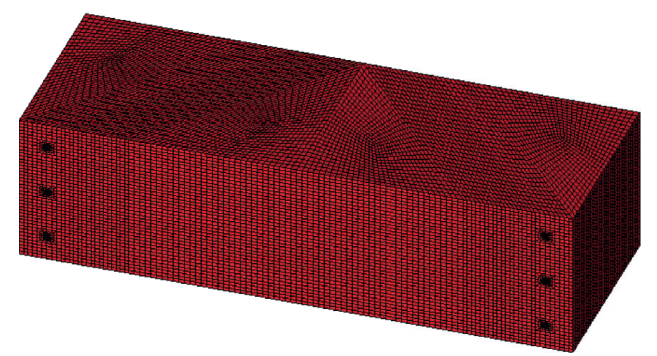

(c)

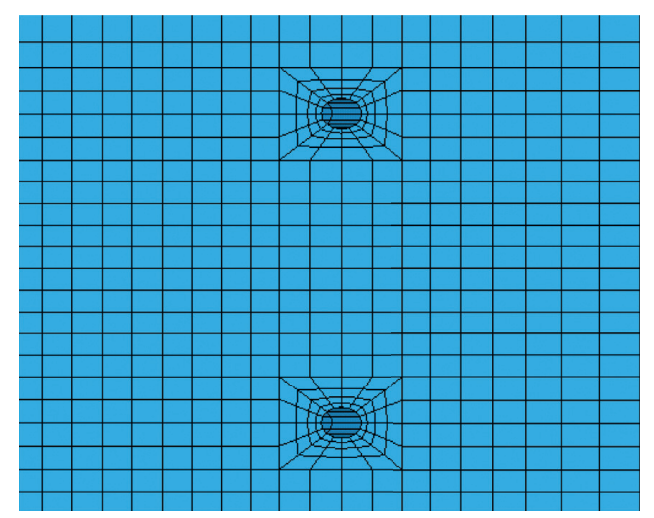

(b)

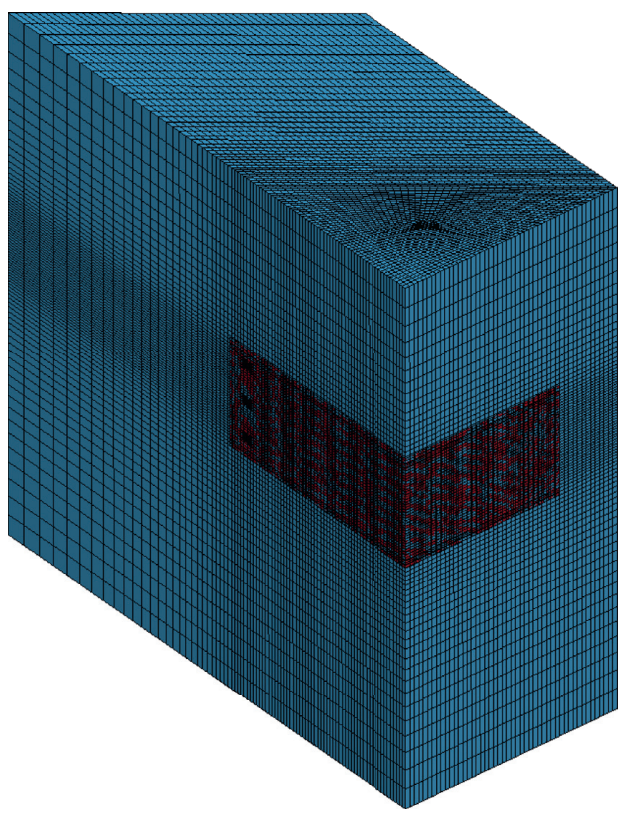

(d)

Figure 5: Grid model diagram. (a) Grid division of local explosives and gun mud. (b) Grid division of local blastholes area. (c) Meshing of air domain. (d) Meshing of fluid-structure coupling semimodel.

TABle 2: Physical and mechanical parameters of air.

\begin{tabular}{lccccccccc}
\hline Density $\left(\mathrm{kg} / \mathrm{m}^{3}\right)$ & Energy per unit volume $\left(\mathrm{MPa} / \mathrm{m}^{3}\right)$ & $C_{0}$ & $C_{1}$ & $C_{2}$ & $C_{3}$ & $C_{4}$ & $C_{5}$ & $C_{6}$ \\
\hline 1.290 & 0.25 & 0 & 0 & 0 & 0 & 0.4 & 0.4 & 0 \\
\hline
\end{tabular}

TABle 3: Limestone HJC model parameters.

\begin{tabular}{lccc}
\hline Parameter & Value & Parameter & Value \\
\hline Mass density $\left(\mathrm{kg} / \mathrm{m}^{3}\right)$ & 2300 & Crushing pressure $(\mathrm{MPa})$ & 20 \\
Shear modulus $(\mathrm{MPa})$ & 10093 & Fracture volume strain & 0.00125 \\
Standardized bond strength & 0.55 & Locking pressure $(\mathrm{GPa})$ & 2 \\
Normalized pressure hardening & 1.23 & Locked volume strain & 0.174 \\
Strain rate factor & 0.0097 & Damage constant $D_{1}$ & 0.04 \\
Pressure hardening index & 0.89 & Damage constant $D_{2}$ & 1 \\
Quasistatic uniaxial compressive strength $(\mathrm{MPa})$ & 60 & Pressure constant $K_{1}(\mathrm{GPa})$ & 39 \\
Maximum stretching hydrostatic pressure $(\mathrm{MPa})$ & 4 & Pressure constant $K_{2}(\mathrm{GPa})$ & -223 \\
Plastic strain before fracture $(\mathrm{MPa})$ & 0.01 & Pressure constant $K_{3}(\mathrm{GPa})$ & 550 \\
\hline
\end{tabular}


TABLe 4: Physical and mechanical parameters of explosives.

\begin{tabular}{lccccccc}
\hline Density $\left(\mathrm{kg} / \mathrm{m}^{3}\right)$ & Detonation velocity $(\mathrm{m} / \mathrm{s})$ & Initial specific internal energy $(\mathrm{GPa})$ & $A(\mathrm{GPa})$ & $B(\mathrm{GPa})$ & $R_{1}$ & $R_{2}$ & $\omega$ \\
\hline 1244 & 3600 & 4.192 & 214.4 & 0.182 & 4.2 & 0.9 & 0.15 \\
\hline
\end{tabular}

TABle 5: Physical and mechanical parameters of gun mud.

\begin{tabular}{lcccc}
\hline Density $\left(\mathrm{kg} / \mathrm{m}^{3}\right)$ & Shear modulus $(\mathrm{MPa})$ & Poisson's ratio & Friction angle $(\mathrm{rad})$ & Cohesion $(\mathrm{MPa})$ \\
\hline 1850 & 20 & 0.28 & 0.56 & 0.18 \\
\hline
\end{tabular}

generally $\lambda_{1}$ is $0.5 \sim 5.5$, most of which are between 0.8 and 2.0 , and the maximum value of $\lambda_{1}$ is 30 . If the ratio of the horizontal stresses average value $\sigma_{H \cdot a n}$ and $\sigma_{V}$ is used to express the lateral pressure coefficient $\left(\lambda_{a v}=\sigma_{H \cdot a n} / \sigma_{V}\right)$, generally $\lambda_{a v}$ is $0.5 \sim 5.0$, most of which are $0.8 \sim 1.5$. China's actual data $\lambda_{a v}$ is between 0.8 and 3.0, $\lambda_{a v}<0.8$ accounted for about $30 \%, \lambda_{a v}=0.8 \sim 1.2$ accounted for about $40 \%$, and $\lambda_{a v}>1.2$ accounted for about $30 \%$ [26]. Based on the above existing research results, $\lambda_{a v}=1.1$ is selected to quantify the horizontal stress on the model, which is

$$
\sigma_{H}=\lambda_{a v} \sigma_{V}
$$

where $\sigma_{H}$ is the horizontal stress, $\mathrm{Pa}$.

Combining the obtained $\sigma_{V}$, the horizontal stress is 1.25 MPa from equation (6).

Before the excavation of the underground engineering, the rock mass is in a balanced state under the original rock stress condition. Due to excavation disturbance, the original balanced state is destroyed, and the rock mass stress is redistributed until reaching a new balance. The surrounding rock stress state after redistribution is called the redistributed stress state, and the stress at this time is called the redistributed stress [26].

It is generally recognized that the distribution stress range of surrounding rock caused by the excavation of underground caverns is $6 R_{0}\left(R_{0}\right.$ is the radius of the circular cavern for underground engineering). The actual tunnel which this study based on has a section radius of $7.38 \mathrm{~m}$. Combined with the above analysis, the redistribution of rock mass stress should be considered in this model.

For a hard and dense massive rock mass, when the natural stress is approximately equal to or less than half of its uniaxial compressive strength, the surrounding rock will be elastically deformed after the excavation of the underground cavern. This type of surrounding rock can be approximately regarded as a homogeneous, continuous, and isotropic linear elastomer, and the redistributed stress of the surrounding rock can be calculated by the method of elastic mechanics. It is known that the compressive strength of argillaceous limestone is $70 \mathrm{MPa}$, and both $\sigma_{V}$ and $\sigma_{H}$ are less than $35 \mathrm{MPa}$; applying the method of elastic mechanics to calculate the rock mass distribution stress of the model, the problem can be simplified to the mechanical model shown in Figure 6.

According to the previous studies, when the natural stresses $\sigma_{V}$ and $\sigma_{H}$ and the hole radius $R_{0}$ are constant, the redistributed stress of the elastic surrounding rock is a

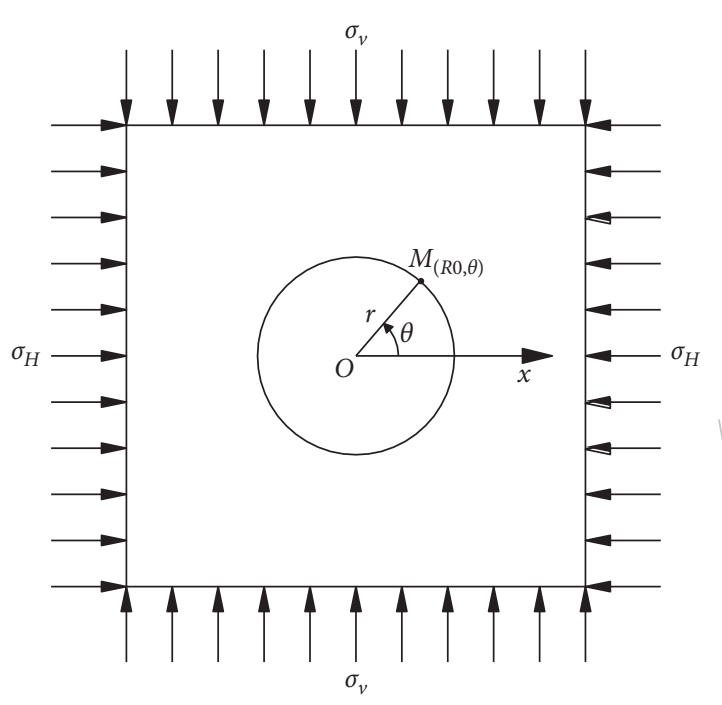

FIGURE 6: Simplified model for stress analysis of surrounding rock in underground engineering.

function of the calculated point position $(r, \theta)$; taking $\lambda=\sigma_{h} / \sigma_{v}$, when $1 / 3<\lambda<3, \sigma_{\theta}$ in the surrounding rock of the cave wall are all compressive stresses and the stress distribution is relatively uniform. Let $r=R_{0}$; then the redistributed stress on the wall of the cave is given by

$$
\left\{\begin{array}{l}
\sigma_{r}=0, \\
\sigma_{\theta}=\sigma_{h}+\sigma_{v}-2\left(\sigma_{h}-\sigma_{v}\right) \cos 2 \theta, \\
\tau_{r \theta}=0,
\end{array}\right.
$$

where $\tau_{r \theta}$ is the natural shear stress on the cave wall, and its value is $0, \sigma_{r}=0$, only $\sigma_{\theta}$ works, it is a unidirectional stress state, and the cave wall is most likely to be damaged at this time. The value of $\sigma_{\theta}$ on the cave wall is only related to the natural stress state and the position of the calculation point $\theta$ but has nothing to do with the cave size $R_{0}$.

In summary, we can get the rock weight distribution stresses $\sigma_{V}=2.61 \mathrm{MPa}$ and $\sigma_{H}=1.83 \mathrm{MPa}$; all are compressive stress.

\section{Simulation Result Analysis}

4.1. The Expansion and Evolution of the Cut Cavity and the Expansion Process of Blasting Crackle. After the explosives were detonated, the explosion energy spread outside along the axis of the cylindrical explosive in a very short time, and the 
effective stress of the explosive component increased instantly. This high stress was transmitted to the air domain at the common nodes with the explosive components and then acted on the rock element close to the explosive unit through a fluidsolid coupling algorithm. The rock element would automatically fail after the stress on the rock element reached the set failure value. According to the blastholes layout shown in Figure 4, the numerical simulation analysis of the simultaneous blasting was carried out. And according to the expansion and evolution process of the cut cavity in Figure 7, it can be seen that the rocks near the bottom of the columnar explosive were the first to be destroyed, and then the explosive propagated along the axis of the charge to the face of the tunnel. When $t=0.72 \mathrm{~ms}$, that is, $0.72 \mathrm{~ms}$ after the explosive detonated, the explosive energy caused the rock fissures to continue to expand, and the broken circles of the two rows of blastholes were basically connected. When $t=1.68 \mathrm{~ms}$, due to the small distance between the bottoms of the two rows of blastholes, a through failure surface was formed between the two rows of blastholes; in the outer position of the blastholes, as the distance between the two rows of blastholes gradually increased and although a through failure surface could not be formed, the expansion of the cracks caused the rock to be further broken. Due to the angle between the blastholes and the face of the tunnel, the explosion formed a component force perpendicular to the bottom surface of the cut cavity. Under this force, the rock between the two rows of blastholes separated from the surrounding rock mass and was thrown toward the face of the tunnel, and when $t=2.34 \mathrm{~ms}$, the cut cavity was finally formed.

The rock-breaking effect and crack propagation process of blasting with two symmetrical blastholes are shown in Figure 8.

4.2. Numerical Simulation Method and Rationality Verification. The rock-breaking condition of the cut cavity internal structure is sectioned from $X, Y$, and $Z$ directions. The position of the $Z$-direction section of the cavity and the slice diagram is shown in Figure 9.

As can be seen from Figure 9, the broken through surface caused by blasting in two rows of blastholes at footage of $1.477 \mathrm{~m}$ caused the rock inside and outside the through surface to separate. Therefore, it is judged that the blasting footage of the simulation result is $1.477 \mathrm{~m}$.

According to the actual measurement of the tunnel blasting on-site, the utilization rate of the blastholes in the blasting project was $85 \%$; that is, the actual rock-breaking footage of the cutting holes was $1.36 \mathrm{~m}$. Comparing the measured data with the simulation results, it can be seen that the absolute error is $0.117 \mathrm{~m}$, and the relative error is $8.6 \%$ [27]. This verifies the feasibility and accuracy of the numerical simulation method.

4.3. Influence of Surrounding Rock Stress. On the basis of verifying the accuracy of the numerical simulation results, the model without surrounding rock stress was reestablished, and the volume change over time of the rock caused by unit failure during the blasting process was measured, as shown in Figure 10.
The volume change of the model without surrounding rock stress was larger than that with surrounding rock stress, which indicated that the actual surrounding rock stress has a clamping effect that cannot be ignored in the cut blasting area. Furthermore, the model cut blasting footage without surrounding rock stress is $1.686 \mathrm{~m}$, the absolute error is $0.326 \mathrm{~m}$, and the relative error is $24 \%$, so the accuracy of the simulation results is greatly reduced, and accordingly, the predictive ability of the model is reduced. It can be seen that it is necessary to consider the existence of surrounding rock stress in the simulation study.

\section{Research on Optimization of Wedge Cut Blasting Mode}

5.1. Detonation Sequence and Delay Time. The analysis of the expansion and evolution process of the cut blasting cavity and the previous study [28] show that the key to successful cut blasting is the synergy of symmetrical blastholes. Based on this, the charge of the left and right blastholes is controlled to be the maximum single-segment detonating charge, and the six-hole simultaneous cut blasting is optimized to be detonated from upper to lower position in three segments. The detonation sequence of the blastholes is shown in Figure 11.

In order to better study the delay time between segments and avoid the superimposition of two segments vibration velocities generated by blasting on the time axis, a two-hole blasting model was first established; that is, only the first segment of the blastholes was detonated. The time-history curve of the particles' resultant vibration velocity of the double-hole blasting model is selected for analysis, and the typical resultant vibration velocity waveform of the double-hole blasting is shown in Figure 12 .

As shown in Figure 13, a large number of monitoring points in the model were selected, we can find that the duration of the vibration process caused by double-hole blasting is $4 \sim 8 \mathrm{~ms}$. Based on the model accuracy verification, the segment detonation delay times of $1 \mathrm{~ms}, 5 \mathrm{~ms}, 8 \mathrm{~ms}$, $10 \mathrm{~ms}, 12 \mathrm{~ms}$, and $15 \mathrm{~ms}$ were set.

5.2. Vibration Velocity Analysis of Rock Particles. The ratio of the difference between the Peak Particle Velocity (PPV) during the simultaneous explosion and the PPV under the corresponding delay time to the PPV during the simultaneous explosion multiplied by $100 \%$ is the vibration reduction ratio (VRR) defined in this paper.

When selecting the monitoring points of the rock model and extracting and analyzing the vibration velocity characteristics and vibration reduction ratio of different segmented delay times, in order to prevent the boundary conditions (nonreflective boundary and fixed boundary conditions) from affecting the accuracy of the simulation results, the boundary element was hidden, and then the vibration velocity monitoring points on the bottom, top, side, and back of the model were set. The location of the monitoring points is shown in Figure 13. 


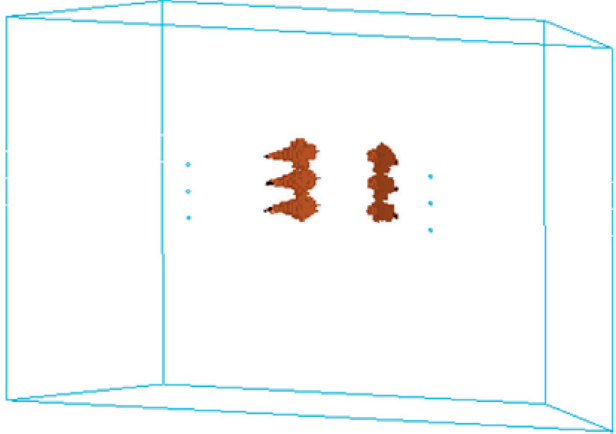

(a)

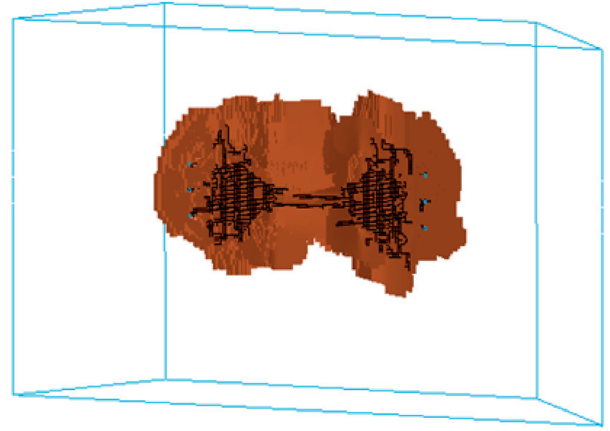

(c)

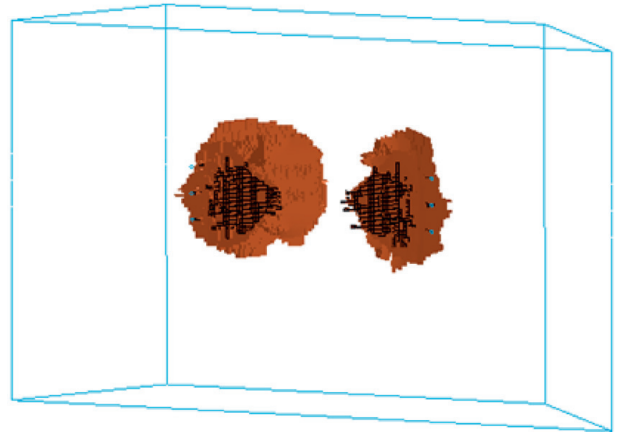

(b)

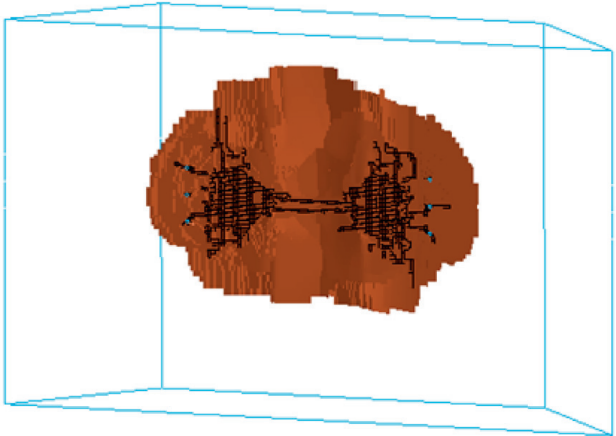

(d)

Figure 7: The expansion and evolution process of the cut cavity: (a) $t=0.12 \mathrm{~ms}$, (b) $t=0.72 \mathrm{~ms}$, (c) $t=1.68 \mathrm{~ms}$, and (d) $t=2.34 \mathrm{~ms}$.

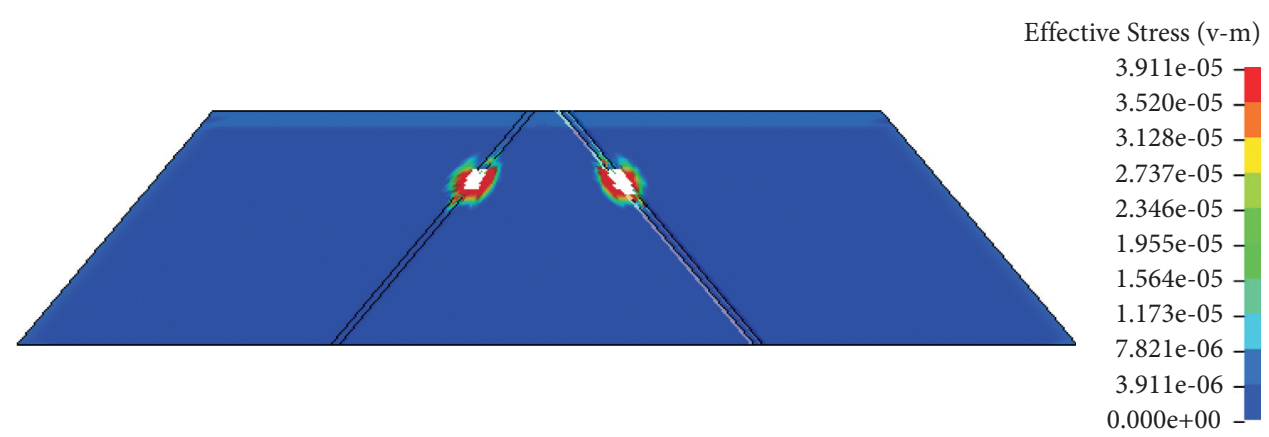

(a)

Effective Stress (v-m)

3.911e-05 -

3.520e-05 -

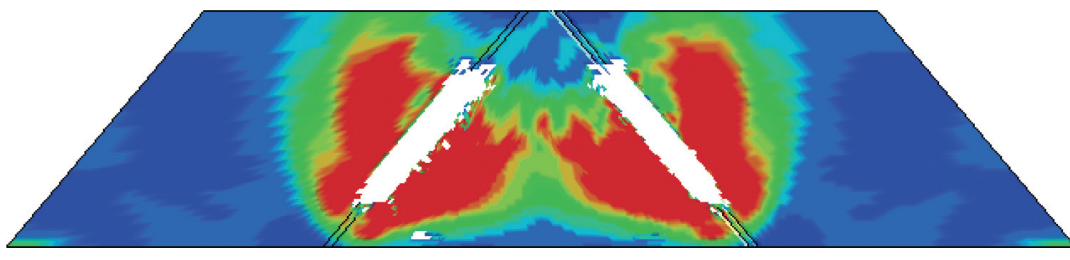

$3.128 \mathrm{e}-05-$

$2.737 \mathrm{e}-05$

2.346e- 05 -

$1.955 \mathrm{e}-05-$

$1.564 \mathrm{e}-05$

$1.173 \mathrm{e}-05$

7.821e-06

$3.911 \mathrm{e}-06$

$0.000 \mathrm{e}+00$

(b)

Figure 8: Continued. 


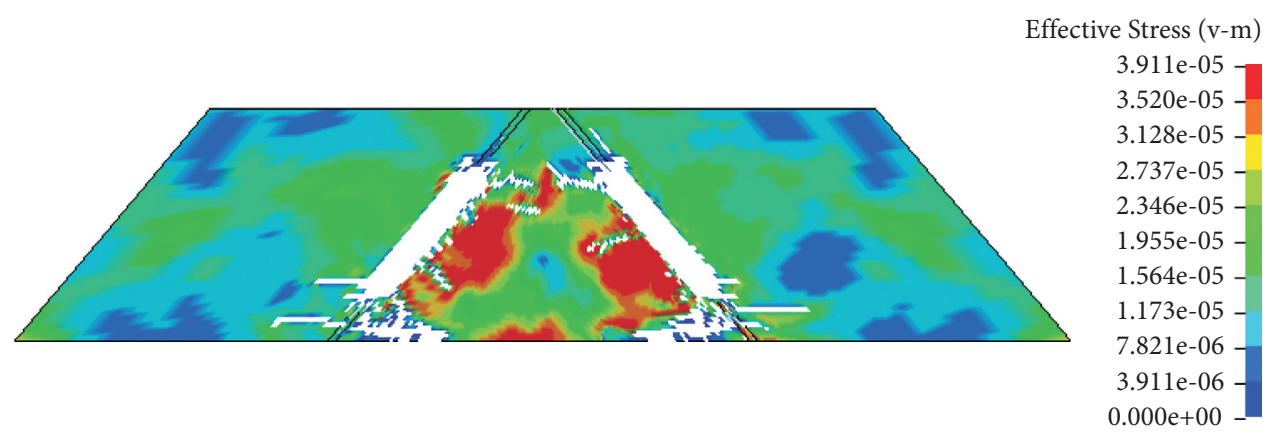

(c)

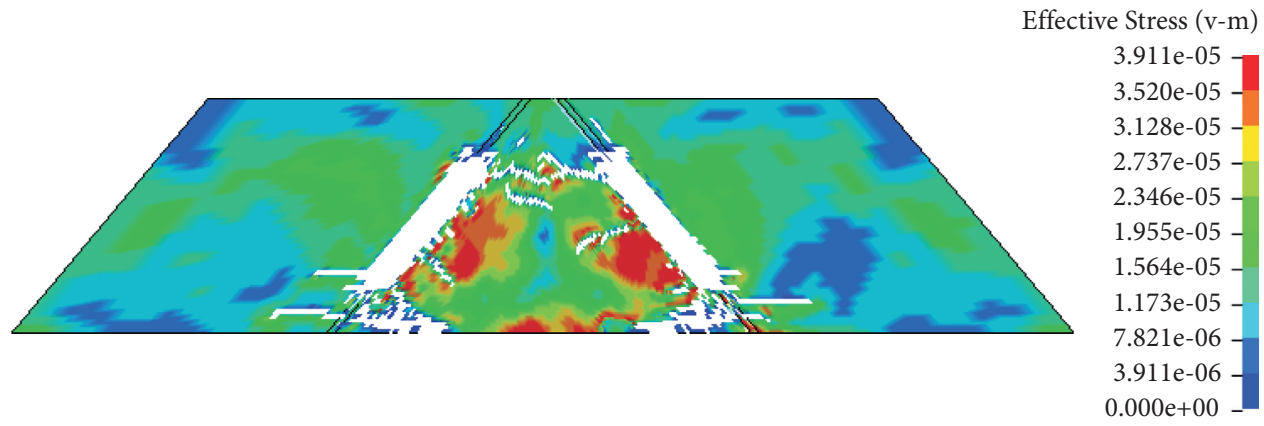

(d)

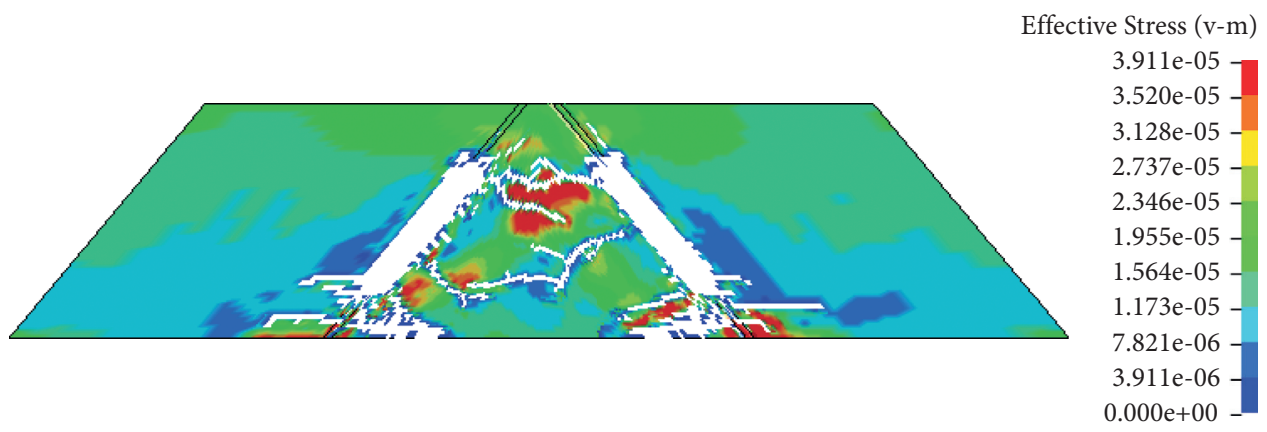

(e)

FIGURE 8: Crack propagation process of wedge-shaped double-hole blasting: (a) $t=0.059 \mathrm{~ms}$, (b) $t=0.54 \mathrm{~ms}$, (c) $t=1.38 \mathrm{~ms}$, (d) $t=1.439 \mathrm{~ms}$, and (e) $t=2.819 \mathrm{~ms}$.

The closest distance between the monitoring points and the explosive component is greater than 150 times the charge radius. So the monitoring points are within the seismic wave action range, and the vibration velocity curve of the monitoring points can accurately judge the detonation delay time feasibility of the two separate blastholes in the numerical model. The resultant vibration velocity waveform of the particles at bottom of the model under different delay times between each segment is shown in Figure 14.

As shown in Figure 14, a large number of monitoring points in the model were selected; we can find that when the delay time between segments is less than $8 \mathrm{~ms}$, the blasting vibration velocity will be superimposed on the time axis; when the delay time is $1 \mathrm{~ms}$, the peak blasting vibration velocity of the subsequent blastholes may exceed that of the first blastholes due to superposition; when the delay time is greater than $8 \mathrm{~ms}$, the vibration velocity of each segment is independent of the time axis, and no superimposition of vibration velocity will occur.

Table 6 lists the peak particle resultant velocity of the monitoring points in the model under the different delay times between each segment. From this table, the trend graph of the average vibration reduction ratio can be obtained:

From Figure 15, it is clear that when the delay time is $10 \mathrm{~ms}$, the vibration velocity generated by the explosive 

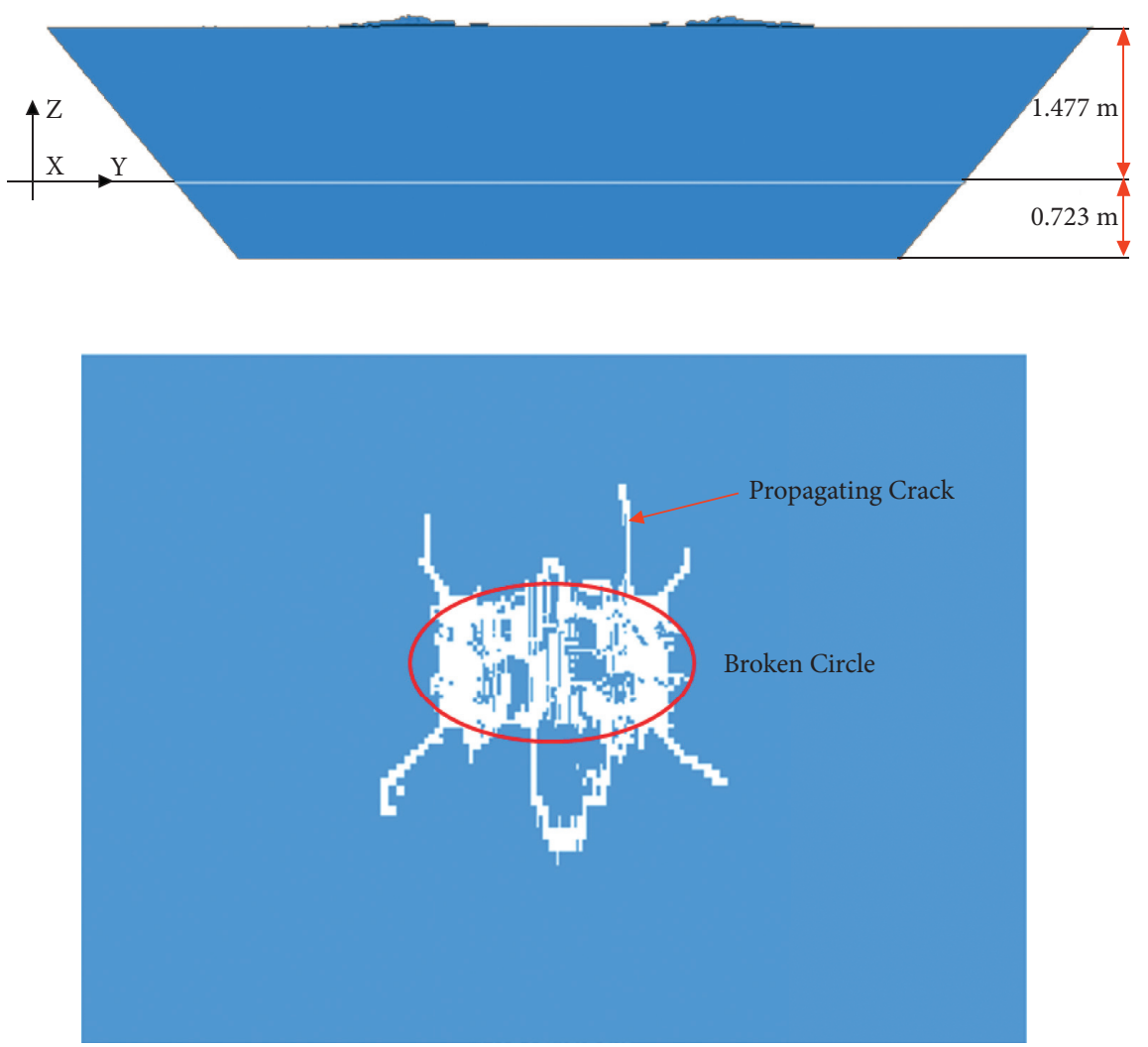

Figure 9: The position of the $Z$-direction section of the cavity and the slice diagram.

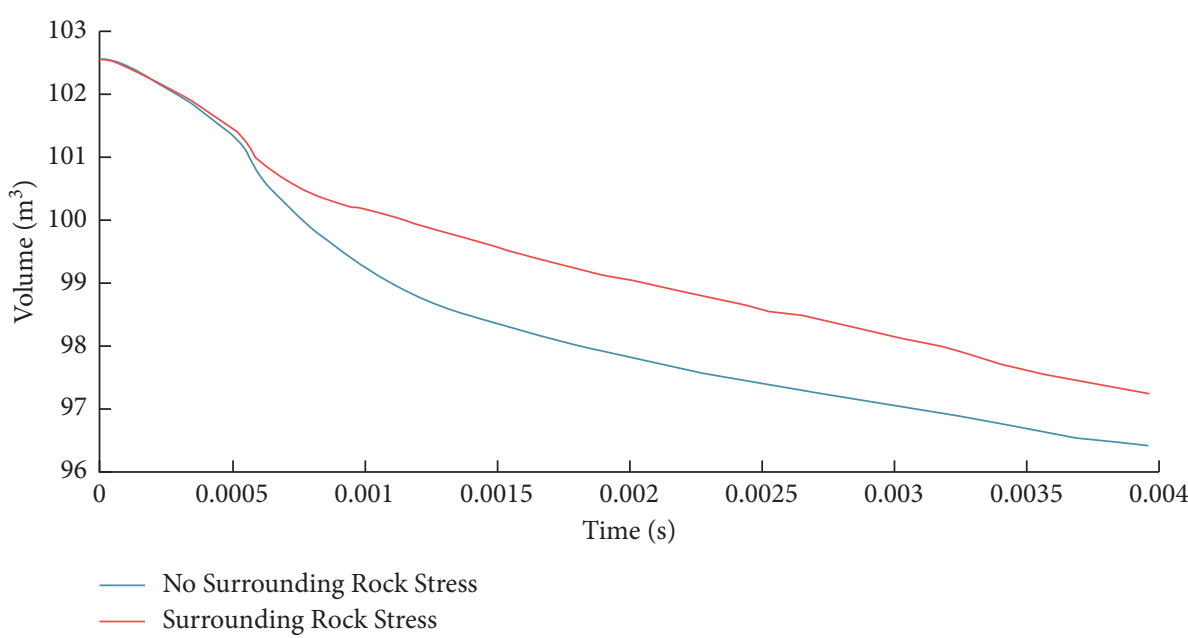

FIgURE 10: Time-history curve of rock volume change with or without surrounding rock stress.

blasting of each segment is independent of the time axis, and the average vibration reduction rate reaches the highest value, up to $18 \%$.

5.3. Blasting Effect Analysis. Figure 16 shows the blasting rock volume time-history changes under simultaneous blasting and different segmented delay times.

It can be seen from Figure 16 that the model volume change is the largest when the cutting holes are simultaneously blasted. Correspondingly, the failure of the model unit is also the largest, which shows that the blasting power of this blasting method is the largest. Among the different segmented delay times, the volume change is the largest when the delay time is $1 \mathrm{~ms}$. And the delay time continues to increase, which is not in a linear relationship with the volume change. When the delay time is $10 \mathrm{~ms}$, not only can the cut blasting be successfully realized, but also the volume change is still good. Although the volume change of the cut blasting at $10 \mathrm{~ms}$ is reduced compared with 


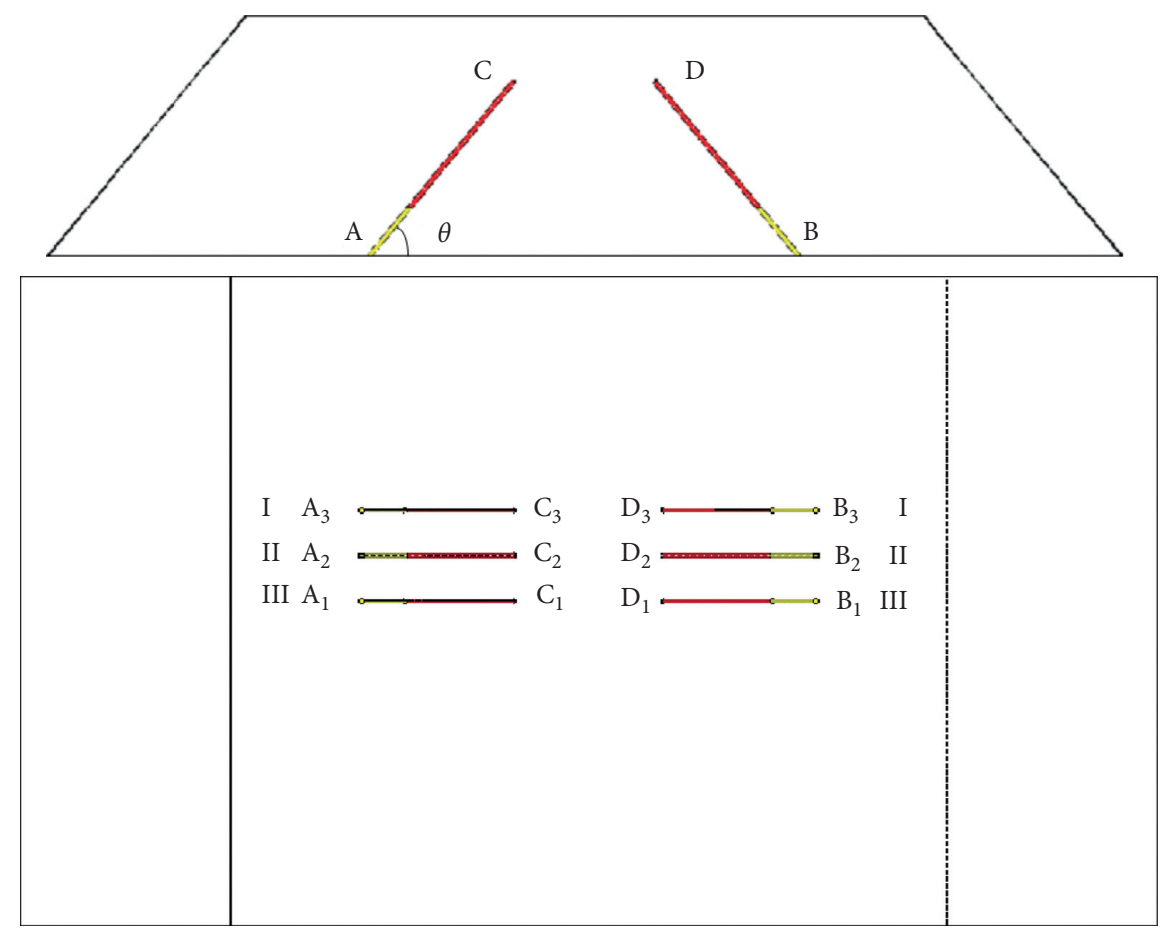

FIgURe 11: Detonation sequence of cut blastholes.

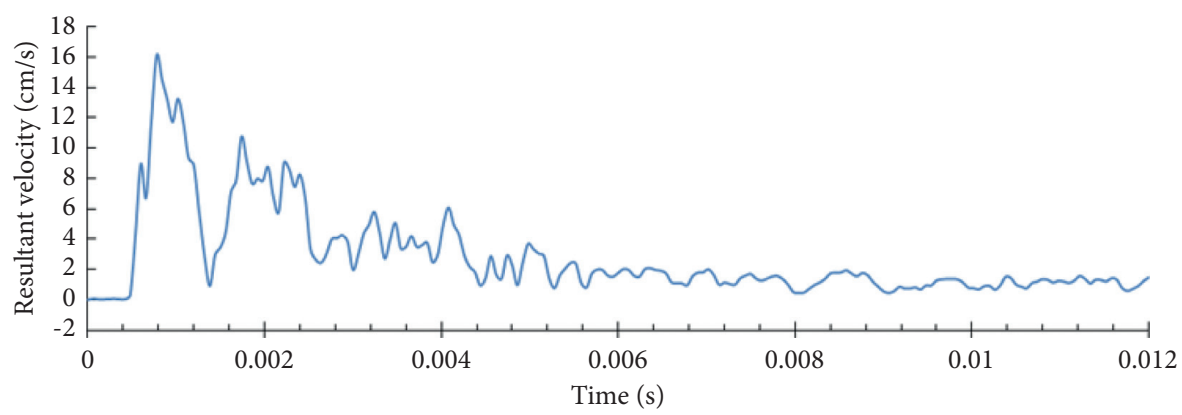

FIGURE 12: Waveform diagram of typical resultant vibration velocity of double-hole blasting.

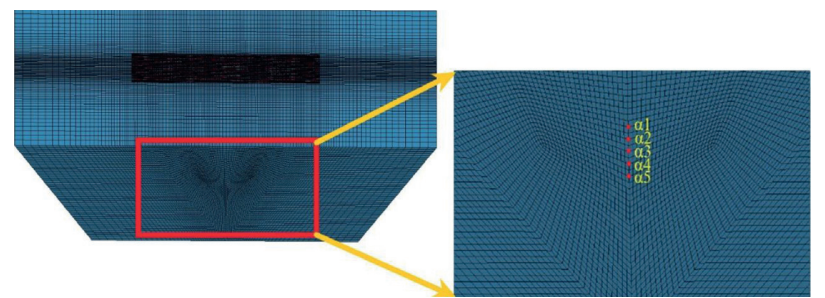

(a)
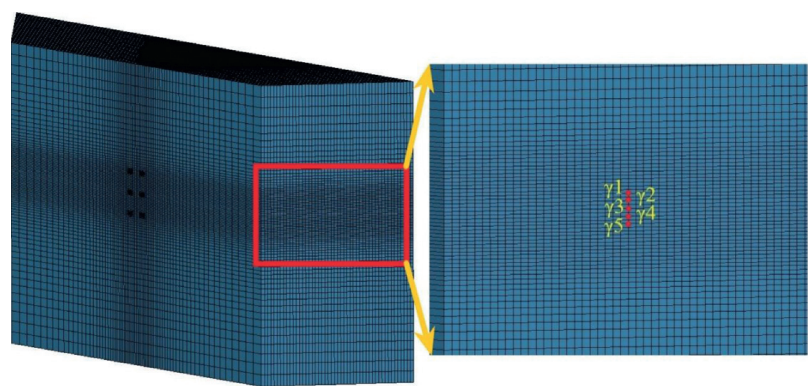

(c)

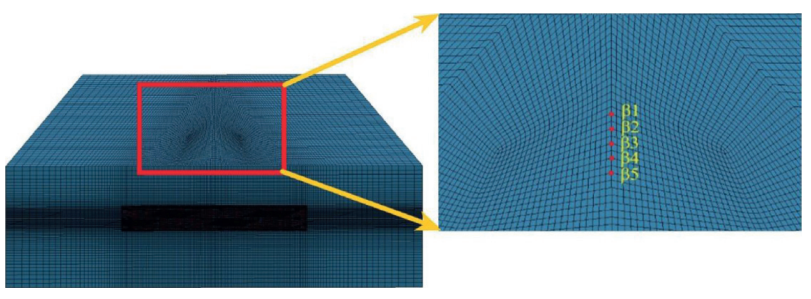

(b)

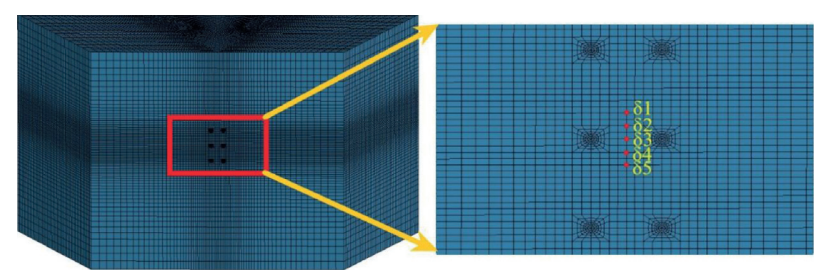

(d)

FIGURE 13: Monitoring points location. (a) Bottom monitoring points. (b) Top monitoring points. (c) Side monitoring points. (d) Back monitoring points. 


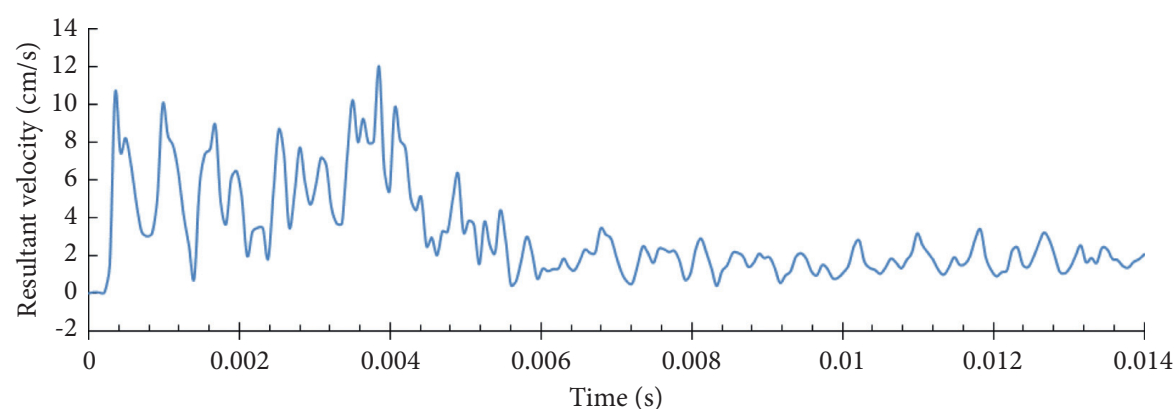

(a)

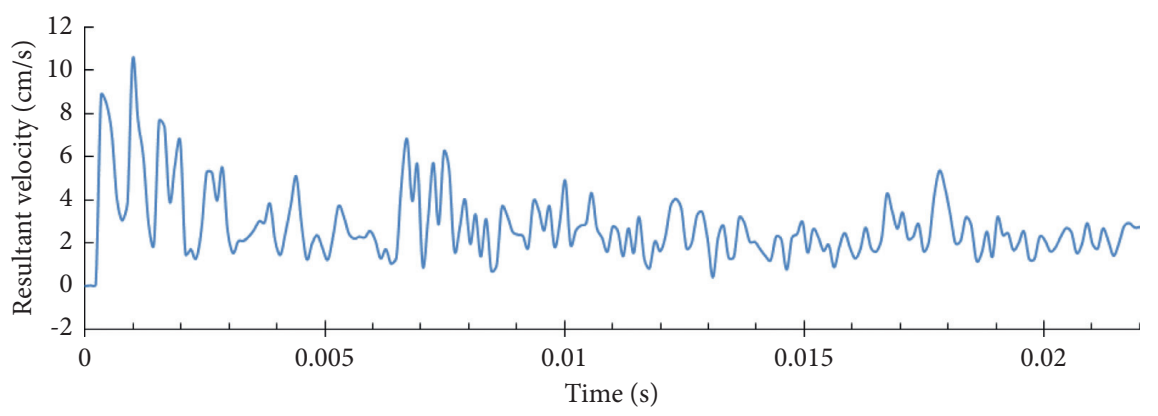

(b)

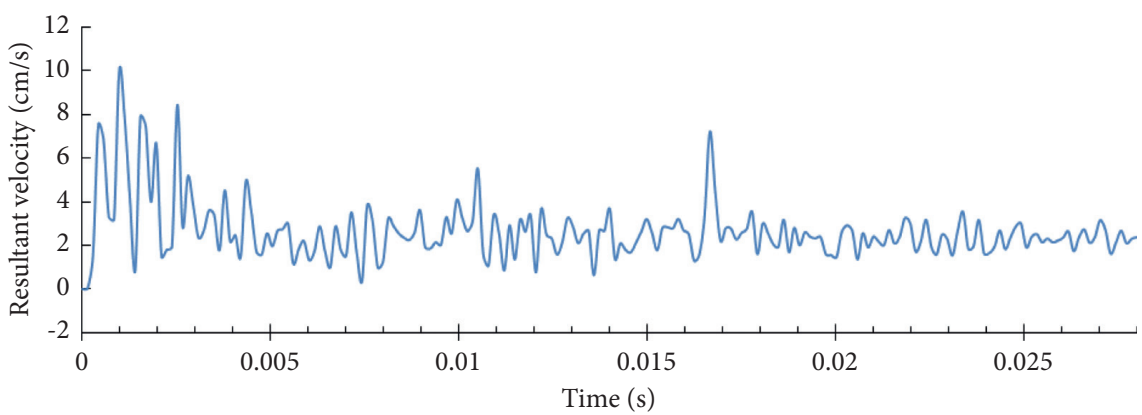

(c)

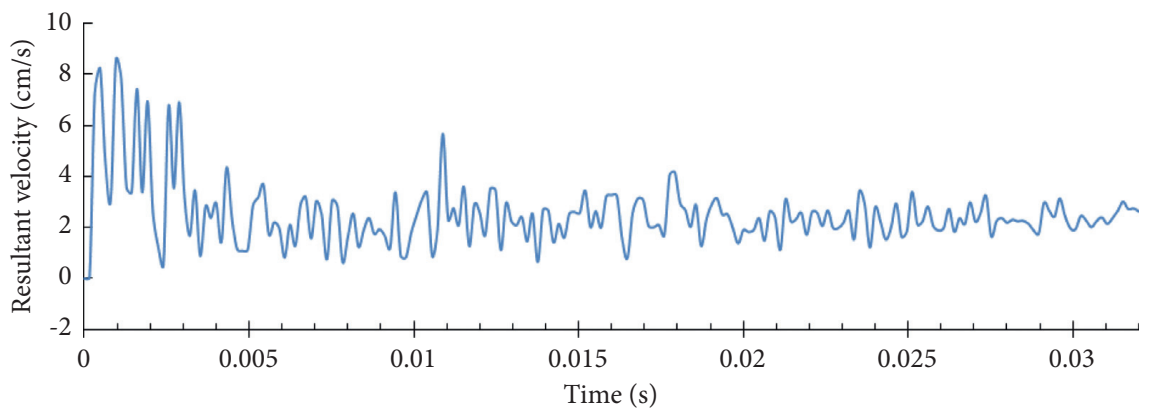

(d)

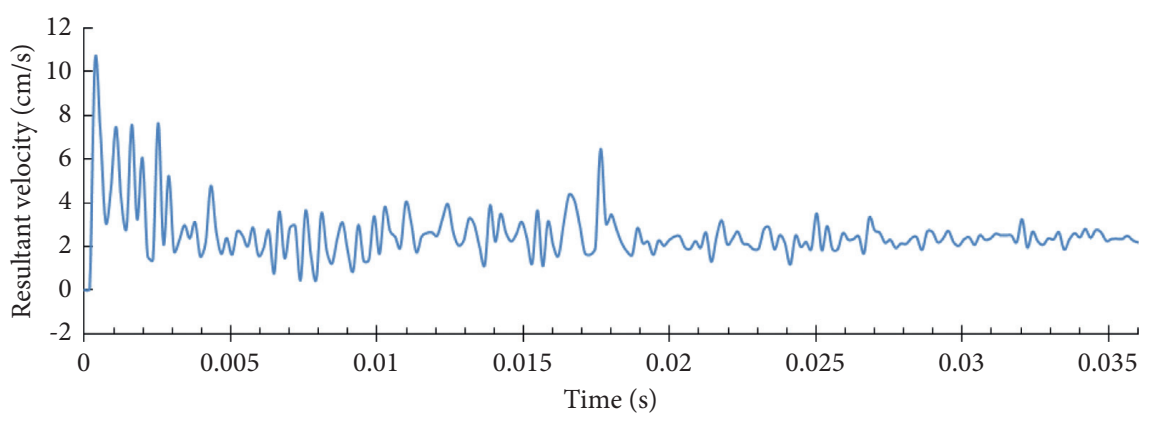

(e)

Figure 14: Continued. 


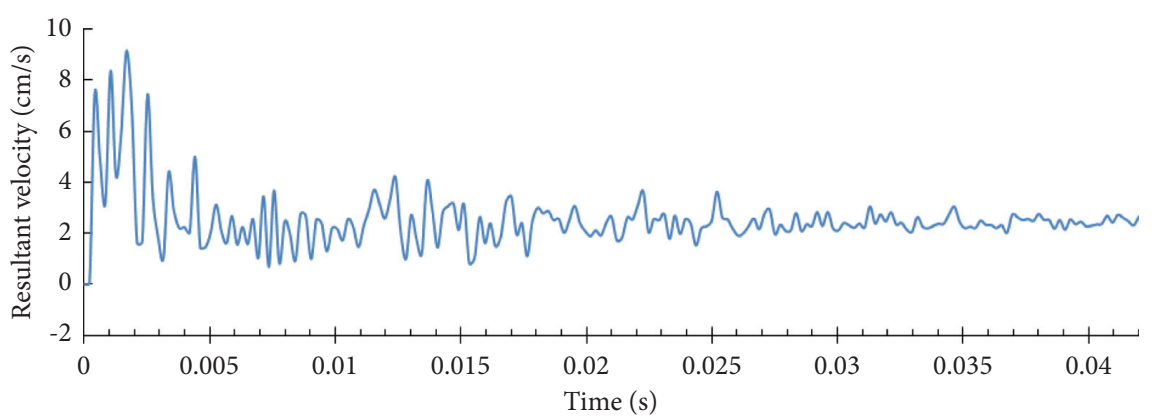

(f)

FiguRE 14: Waveform diagram of typical resultant vibration velocity under different delay times: (a) $\Delta(t)=1 \mathrm{~ms}$. (b) $\Delta(t)=5 \mathrm{~ms}$. (c) $\Delta(t)=$ $8 \mathrm{~ms}$. (d) $\Delta(t)=10 \mathrm{~ms}$. (e) $\Delta(t)=12 \mathrm{~ms}$. (f) $\Delta(t)=15 \mathrm{~ms}$.

TABLE 6: The peak particle resultant velocity of rock.

\begin{tabular}{|c|c|c|c|c|c|c|c|c|c|c|c|c|c|c|c|c|}
\hline Object & & Simultaneous & $1 \mathrm{~ms}$ & VRR & $5 \mathrm{~ms}$ & VRR & $8 \mathrm{~ms}$ & VRR & $\begin{array}{c}10 \mathrm{~ms} \\
(\%)\end{array}$ & VRR & $\begin{array}{c}12 \mathrm{~ms} \\
(\%)\end{array}$ & VRR & $\begin{array}{c}15 \mathrm{~ms} \\
(\%)\end{array}$ & VRR & $\begin{array}{c}\text { Double } \\
\text { hole }\end{array}$ & VRR \\
\hline \multirow{5}{*}{$\begin{array}{l}\text { Bottom } \\
\text { monitoring } \\
\text { point }\end{array}$} & $\alpha_{1}$ & 12 & 10.1 & $16 \%$ & 9.5 & $21 \%$ & 10.1 & 16 & 9.5 & 21 & 11.5 & 4 & 10.1 & $16 \%$ & 11.5 & $4 \%$ \\
\hline & $\alpha_{2}$ & 11.6 & 11.7 & $-1 \%$ & 10.7 & $8 \%$ & 9.7 & 16 & 9.5 & 18 & 9.2 & 21 & 11.7 & $-1 \%$ & 9.9 & $15 \%$ \\
\hline & $\alpha_{3}$ & 11.5 & 11.4 & $1 \%$ & 11.8 & $-3 \%$ & 9 & 22 & 9.7 & 16 & 9.3 & 19 & 11.4 & $1 \%$ & 9.8 & $15 \%$ \\
\hline & $\alpha_{4}$ & 11.6 & 10.1 & $13 \%$ & 11 & $5 \%$ & 9.4 & 19 & 9.7 & 16 & 9.2 & 21 & 9.5 & $18 \%$ & 11.4 & $2 \%$ \\
\hline & $\alpha_{5}$ & 11.4 & 10.3 & $10 \%$ & 9.5 & $17 \%$ & 9.3 & 18 & 9.3 & 18 & 9.2 & 19 & 8.6 & $25 \%$ & 11.5 & $-1 \%$ \\
\hline \multirow{5}{*}{$\begin{array}{l}\text { Top monitoring } \\
\text { point }\end{array}$} & $\beta_{1}$ & 27 & 22.7 & $16 \%$ & 21.8 & $19 \%$ & 20.9 & 23 & 20.6 & 24 & 21.5 & 20 & 21.2 & $21 \%$ & 20.3 & $25 \%$ \\
\hline & $\beta_{2}$ & 25.3 & 22.7 & $10 \%$ & 22.5 & $11 \%$ & 21.6 & 15 & 21.3 & 16 & 21.5 & 15 & 20.5 & $19 \%$ & 21 & $17 \%$ \\
\hline & $\beta_{3}$ & 23.8 & 22.4 & $6 \%$ & 23 & $3 \%$ & 22.1 & 7 & 21.8 & 8 & 21.6 & 9 & 19.9 & $16 \%$ & 21.6 & $9 \%$ \\
\hline & $\beta_{4}$ & 22.9 & 22.7 & $1 \%$ & 23.5 & $-3 \%$ & 22.6 & 1 & 22.1 & 3 & 21.5 & 6 & 20.2 & $12 \%$ & 22 & $4 \%$ \\
\hline & $\beta_{5}$ & 23 & 22.9 & $0 \%$ & 23.8 & $-3 \%$ & 22.8 & 1 & 22 & 4 & 21.8 & 5 & 20.8 & $10 \%$ & 22.4 & $3 \%$ \\
\hline \multirow{5}{*}{$\begin{array}{l}\text { Side monitoring } \\
\text { point }\end{array}$} & $\gamma_{1}$ & 20.7 & 20.5 & $1 \%$ & 20.3 & $2 \%$ & 19.1 & 8 & 18.4 & 11 & 18.8 & 9 & 17.9 & $14 \%$ & 20.3 & $2 \%$ \\
\hline & $\gamma_{2}$ & 20.7 & 20.5 & $1 \%$ & 20.4 & $1 \%$ & 19.1 & 8 & 18.2 & 12 & 19 & 8 & 18 & $13 \%$ & 20.4 & $1 \%$ \\
\hline & $\gamma_{3}$ & 20.7 & 20.5 & $1 \%$ & 20.4 & $1 \%$ & 19.1 & 8 & 17.9 & 14 & 19.1 & 8 & 18.1 & $13 \%$ & 20.4 & $1 \%$ \\
\hline & $\gamma_{4}$ & 20.7 & 20.4 & $1 \%$ & 20.4 & $1 \%$ & 19 & 8 & 17.9 & 14 & 19.3 & 7 & 18.3 & $12 \%$ & 20.4 & $1 \%$ \\
\hline & $\gamma_{5}$ & 20.6 & 20.3 & $1 \%$ & 20.4 & $1 \%$ & 19 & 8 & 18 & 13 & 19.4 & 6 & 18.5 & $10 \%$ & 20.3 & $1 \%$ \\
\hline \multirow{5}{*}{$\begin{array}{l}\text { Back } \\
\text { monitoring } \\
\text { point }\end{array}$} & $\delta_{1}$ & 30.1 & 24 & $20 \%$ & 21.6 & $28 \%$ & 21.8 & 28 & 21.1 & 30 & 22 & 27 & 22.8 & $24 \%$ & 21.6 & $28 \%$ \\
\hline & $\delta_{2}$ & 30.3 & 23.9 & $21 \%$ & 21.6 & $29 \%$ & 21.8 & 28 & 21.1 & 30 & 22.1 & 27 & 22.7 & $25 \%$ & 21.5 & $29 \%$ \\
\hline & $\delta_{3}$ & 30.5 & 23.7 & $22 \%$ & 21.6 & $29 \%$ & 21.8 & 29 & 21 & 31 & 22.2 & 27 & 22.6 & $26 \%$ & 21.6 & $29 \%$ \\
\hline & $\delta_{4}$ & 30.7 & 23.8 & $22 \%$ & 21.6 & $30 \%$ & 21.7 & 29 & 21.1 & 31 & 22.3 & 27 & 22.5 & $27 \%$ & 21.6 & $30 \%$ \\
\hline & $\delta_{5}$ & 30.9 & 23.9 & $23 \%$ & 21.6 & $30 \%$ & 21.7 & 30 & 21.1 & 32 & 22.4 & 28 & 22.3 & $28 \%$ & 21.6 & $30 \%$ \\
\hline $\begin{array}{l}\text { Average } \\
\text { vibration } \\
\text { reduction rat }\end{array}$ & & & $9 \%$ & & $11 \%$ & & $16 \%$ & & $18 \%$ & & $16 \%$ & & $16 \%$ & & $2 \%$ & \\
\hline
\end{tabular}

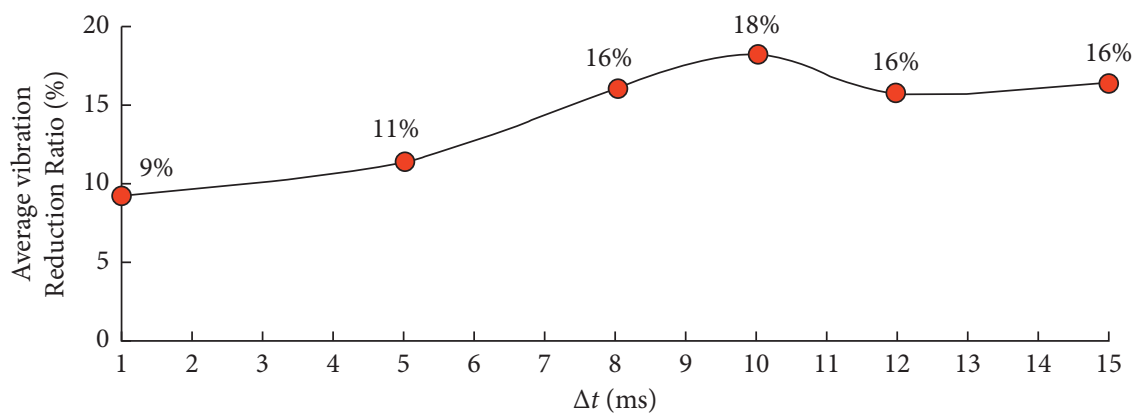

FIgURE 15: Trend graph of the average vibration reduction ratio under different delay times. 


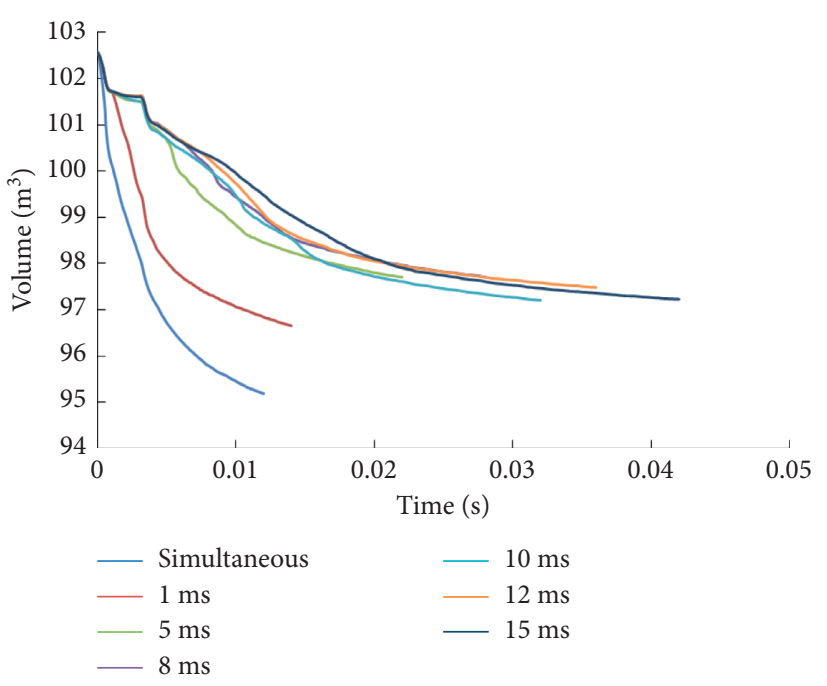

Figure 16: Time-history curve of volume change.

simultaneous blasting, it has little effect on the overall cut blasting, so $10 \mathrm{~ms}$ can be determined as the optimal blasthole delay time.

\section{Conclusions}

The fluid-solid coupling algorithm based on ANSYS/LSDYNA was used to carry out a numerical simulation study on the tunnel wedge cut blasting, and finally, the optimal cutting hole delay time was determined. The main conclusions are as follows:

(1) The tunnel wedge cut blasting footage obtained by the blasting numerical simulation of fluid-solid coupling algorithm based on ANSYS/LS-DYNA is basically consistent with the field measured results, which proves that the model is reasonable and effective. This method can be used in actual engineering to solve the issues about wedge cut blasting.

(2) Comparing the simulation results of the rock model with or without surrounding rock stress, the volume change before and after the blasting of the model without surrounding rock stress is larger than that with surrounding rock stress. It shows that the actual surrounding rock stress has a clamping effect on the cut blasting area and has a certain influence on the cut blasting effect.

(3) Although the delay time between segments can make the blasting seismic waves separate on the time axis, the vibration reduction ratio will not always increase with the increase of the delay time between segments. The actual tunnel is in complex geological conditions. The blasting scheme should be designed on the basis of comprehensive on-site blasting vibration monitoring data and blasting effect evaluation, and the delay time should be adjusted in time according to changes in tunnel conditions; thereby, the best blasting effect can be achieved while reducing the intensity of blasting vibration.
(4) Under this engineering geological condition, a wedge-shaped symmetrical segmented cut blasting method is adopted in which the cutting blastholes are divided into three segments from upper to lower position, and the left-right symmetrical blastholes are divided into one segment. When the delay time is $10 \mathrm{~ms}$, the average vibration reduction ratio is the best, which is reduced by $18 \%$ compared to the sixhole simultaneous blasting. The cut blasting can be successfully achieved, and the blasting effect is the best.

\section{Data Availability}

The data used to support the findings of this study are available from the corresponding author upon request.

\section{Conflicts of Interest}

The authors declare that they have no conflicts of interest.

\section{Acknowledgments}

This research was supported by the National Natural Science Foundation of China (no. 51874189).

\section{References}

[1] R. Kumar, D. Choudhury, and K. Bhargava, "Determination of blast-induced ground vibration equations for rocks using mechanical and geological properties," Journal of Rock Mechanics and Geotechnical Engineering, vol. 8, no. 3, pp. 341349, 2016

[2] P. Dohyun and J. Seokwon, "Reduction of blast-induced vibration in the direction of tunneling using an airdeck at the bottom of a blasthole," International Journal of Rock Mechanics and Mining Sciences, vol. 47, no. 5, pp. 752-761, 2010.

[3] H. K. Verma, N. K. Samadhiya, M. Singh, R. K. Goel, and P. K. Singh, "Blast induced rock mass damage around tunnels," Tunnelling and Underground Space Technology, vol. 71, pp. 149-158, 2018.

[4] C. Li and X. Li, "Influence of wavelength-to-tunnel-diameter ratio on dynamic response of underground tunnels subjected to blasting loads," International Journal of Rock Mechanics and Mining Sciences, vol. 112, pp. 323-338, 2018.

[5] L. F. Triviño, B. Mohanty, and B. Milkereit, "Seismic waveforms from explosive sources located in boreholes and initiated in different directions," Journal of Applied Geophysics, vol. 87, no. 12, pp. 81-93, 2012.

[6] I. A. Onederra, J. K. Furtney, E. Sellers, and S. Iverson, "Modelling blast induced damage from a fully coupled explosive charge," International Journal of Rock Mechanics and Mining Sciences, vol. 58, no. 1, pp. 73-84, 2013.

[7] L. X. Xie, W. B. Lu, Q. B. Zhang, Q. H. Jiang, G. H. Wang, and J. Zhao, "Damage evolution mechanisms of rock in deep tunnels induced by cut blasting," Tunnelling and Underground Space Technology incorporating Trenchless Technology Research, vol. 58, 2016.

[8] W. B. Lu, Z. D. Leng, H. R. Hu, M. Chen, and G. H. Wang, "Experimental and numerical investigation of the effect of blast-generated free surfaces on blasting vibration," European Journal of Environmental and Civil Engineering, vol. 2211 pages, 2018. 
[9] W. Chen, H. Ma, Z. Shen, and D. Wang, "Experiment research on the rock blasting effect with radial jet cracker," Tunnelling and Underground Space Technology, vol. 49, pp. 249-252, 2015.

[10] Y. S. Stepanov, "Maximum fracture zone in solid rock due to explosion of two parallel cylindrical charges," Soviet Mining Science, vol. 10, no. 6, pp. 672-674, 1974.

[11] É. P. Taran and V. Y. Shapiro, "Action of the explosion of a blast hole charge in the design of a direct cut with a compensation hole," Soviet Mining Science, vol. 18, no. 2, pp. 119-122, 1982.

[12] A. K. Chakraborty, P. Pal Roy, J. L. Jethwa, and R. N. Gupta, "Blast performance in small tunnels - a critical evaluation in underground metal mines," Tunnelling and Underground Space Technology, vol. 13, no. 3, pp. 331-339, 1998.

[13] Q. Pei and J. Chen, "Design of combination of smooth blasting and double-wedge cut for roadway excavation," Mining Research and Development, vol. 400, 2009.

[14] Z. Ding, J. Jia, X. Li, L. Ji, L. Yulong, and L. Jinglong, "Experimental study and application of medium-length hole blasting technique in coal-rock roadway," Energy Science \& Engineering, vol. 8, 2020.

[15] B. Zakrisson, W. Bengt, and H. Häggblad, "Numerical simulations of blast loads and structural deformation from nearfield explosions in air," International Journal of Impact Engineering, vol. 38, no. 7, pp. 597-612, 2011.

[16] G. W. Ma and X. M. An, "Numerical simulation of blastinginduced rock fractures," International Journal of Rock Mechanics and Mining Sciences, vol. 45, no. 6, pp. 966-975, 2007.

[17] J. H. Yang, Q. H. Jiang, Q. B. Zhang, and J. Zhao, "Dynamic stress adjustment and rock damage during blasting excavation in a deep-buried circular tunnel," Tunnelling and Underground Space Technology, vol. 71, pp. 591-604, 2018.

[18] M. Mokhtari and A. Alavi Nia, "A parametric study on the mechanical performance of buried X65 steel pipelines under subsurface detonation," Archives of Civil and Mechanical Engineering, vol. 15, no. 3, pp. 668-679, 2015.

[19] W. Wan, J. Yang, G. Xu, and Y. Liu, "Determination and evaluation of Holmquist-Johnson-Cook constitutive model parameters for ultra-high-performance concrete with steel fibers," International Journal of Impact Engineering, vol. 156, Article ID 103966, 2021.

[20] Y. S. Liu, "Study on the mechanical properties and anti-penetration mechanism of steel fiber concrete," University of Science and Technology of China, Langfang, China, pp. 88-91, 2006.

[21] Livermore Software Technology, LS-DYNA R11 Keyword User's Manual, Livermore Software Technology Corporation, Livermore, CA, USA, 2018.

[22] E. El-Danaf, M. Baig, A. Almajid, W. Alshalfan, M. Al-Mojil, and S. Al-Shahrani, "Mechanical, microstructure and texture characterization of API X65 steel," Materials \& Design, vol. 47, pp. 529-538, 2013.

[23] Q. R. Sun, R. Y. Li, Y. Y. Zhao, and Y. x. Sun, "Investigation on parameters of HJC model applied to simulate perforation experiments of reinforced concrete," Engineering Mechanics, vol. 33, no. 8, pp. 248-256, 2016.

[24] K. Liu, Q. Li, C. Wu, X. Li, and J. Li, "A study of cut blasting for one-step raise excavation based on numerical simulation and field blast tests," International Journal of Rock Mechanics and Mining Sciences, vol. 109, pp. 91-104, 2018.

[25] Y. Yuan, C.-f. Yuan, C. Zhu, H.-x. Liu, and S.-z. Wang, "Study on the disaster reduction mechanism of presplitting blasting and reasonable blasting parameters for shallowly buried remnant pillars," Energy Science \& Engineering, vol. 7, no. 6, 2019.

[26] Y. X. Zhang and M. Xu, Rock Mechanics, pp. 129-139, China Construction Industry Press, Beijing, China, 2015.

[27] N. Jiang, T. Gao, C. Zhou, and X. Luo, "Effect of excavation blasting vibration on adjacent buried gas pipeline in a metro tunnel," Tunnelling and Underground Space Technology, vol. 81, pp. 590-601, 2018.

[28] B. Cheng, H. Wang, Q. Zong, Y. Xu, M. Wang, and Q. Zheng, "Study of the double wedge cut technique in medium-depth hole blasting of rock roadways," Arabian Journal for Science and Engineering, vol. 46, no. 5, pp. 4895-4909, 2021. 